Forthcoming, Utilities Policy

August 21, 2001

\title{
Sustainable Regulatory Systems: Laws, Resources, and Values
}

\author{
by \\ Sanford V. Berg ${ }^{1}$
}

\begin{abstract}
Regulators frequently face difficult economic trade-offs in their decision-making. They must know how to assess the effects of policies on stakeholders under conditions of imperfect information. Part of the art of regulation revolves around understanding the linkages between choice of market structure, design of regulatory rules, and institutional requirements. In addition, different aspects of sector performance will be prioritized depending on the nation's level of development. Three factors determine the effectiveness of independent regulatory commissions during periods of change.
\end{abstract}

(1) Resources available to the organization are generally determined by the legal instrument that brought the agency into existence. Budgets require funding mechanisms and procedures promoting accountability. Resource levels and resource mix (such as the percentage of highly motivated professionals) determine the range of activities suitable for the organization.

(2) The legal mandate is interpreted by the courts. Since the law itself is often the product of political compromise, initial legislation may be inadequate for the effective performance of agency duties. Agency initiatives can precede formal legislative revisions, but these are likely to be challenged by some stakeholders.

(3) The values or principles supporting the agency are derived from the national culture and a shared political vision. At the birth of the agency, leaders and key professional staff may not have reached consensus regarding priorities. Agreement on fundamental principles is essential if the agency is to develop a consistent set of policies.

\footnotetext{
${ }^{1}$ The author is Distinguished Service Professor-Economics, University of Florida, and Director, Public Utility Research Center. John Corlett, Daniel Peralta, and Mark Jamison provided helpful comments on earlier versions of this paper. Most of the supporting examples draw upon cases presented at the PURC/World Bank International Training Program on Utility Regulation and Strategy: http://www.purc.org
} 
July 23, 2001

\title{
Fundamentals of Regulatory Systems: Laws, Resources, and Values
}

\author{
by \\ Sanford V. Berg
}

\section{Background}

Nations around the globe have created new government agencies to perform functions previously done by government ministries or government-owned firms. Independent regulatory commissions (IRCs) have been established to curb budget deficits caused by subsidies and to promote infrastructure sector expansion via private participation. The pace of market liberalization and privatization has not meant government withdrawal from the sector; rather, regulatory commissions are generally responsible for providing incentives for operating efficiently, improving service quality, and promoting competition where feasible. The objective of improving sector performance means that leaders of these new agencies have had to help design systems of governance and develop regulatory rules that support these reform objectives.

Reform objectives include:

- Constraining the exercise of monopoly power by incumbent suppliers,

- Stopping subsidies to the sector (to reduce the drain on the Treasury),

- Optimizing the structure of the sector (encouraging competition where feasible),

- Providing incentives for operating efficiency and quality of service,

- Promoting least-cost system expansion (incentives for new investment),

- Stimulating innovation and (for electricity regulators) energy conservation.

Achieving these objectives requires some prioritization, since policymakers must make political and economic trade-offs. Furthermore, the IRC must engage in activities that support these priorities and yield improved sector performance. For the work of the agency to move forward, the agency must possess resources adequate to engage in activities, a legal mandate that legitimizes the activities, and values that uphold the activities. Political and institutional forces that influence the reform process affect each of these three factors.

(1) The legal instrument that brought the agency into existence determines the resources available to the organization. Budgets require funding mechanisms and procedures promoting accountability. Resource level and resource mix (e.g., the percentage of 
highly motivated professionals) determine the range of activities suitable for the organization.

(2) Courts interpret the legal mandate, as it is expressed in the law. Since the law itself is often the product of political compromise, initial legislation may be inadequate for the effective performance of agency duties. Agency initiatives can precede formal legislative revisions, but these are likely to be challenged by some stakeholders.

(3) The values or principles supporting the agency are derived from the national culture and a shared political vision. At the birth of the agency, leaders and key professional staff may not have reached consensus regarding priorities. However, agreement on fundamental principles is essential if the agency is to develop a consistent set of policies.

Both regulators and infrastructure managers need to understand how these three factors contribute to the complex system of regulatory governance that can either block new initiatives or promote innovative policy responses to what are very difficult economic and political problems.

\section{Three Factors Affecting Regulatory Performance}

It is useful to describe in greater detail how the three factors (legal mandate, core agency values, and organizational resources) affect the potential success of daily activities. ${ }^{2}$ If one of the three vital inputs is missing, the function is less likely to be successfully performed. Thus, a number of design questions need to be addressed in establishing the IRC. Let us summarize the elements of each component.

Legal mandate: How clearly defined are the agency's functions? Should the regulatory entity have jurisdiction over one industry, one sector or several sectors? Does the law provide appropriate authority, instruments and appeal procedures? Does the law specify the objectives of the agency, while leaving some flexibility for the development of effective procedures and specific policies that support the objectives established in the law?

Berg, Memon and Skelton (2000) identify activities (or functions) required for effective regulation of prices (rates) in conjunction with incentives for cost-containment, an objective of most new regulatory regimes. The nine functions and their links to prices are as follows:

i. $\quad$ Licensing specifies operating standards that have impacts on costs/tariffs.

ii. Performance standards on quality and reliability have cost and tariff implications.

iii. Monitoring data on costs, revenues, and performance is essential for tariff determination.

iv. Tariff setting determines revenue sufficiency for operating costs, capital costs (returns, asset values, deferred loans), etc.

v. Uniform Accounting Systems provide comparable cost data (generation, transmission, distribution) for tariffs.

vi. Arbitration among firms and consumers is required for tariff and competitive-

\footnotetext{
2 The material in the next few paragraphs draws from Berg, Memon and Skelton (2000).
} 
access disputes.

vii. Management audits promote cost and tariff reduction via yardstick comparisons.

viii. Human resources policies have operating cost and tariff implications.

ix. Reports on costs and tariffs emphasize current and future performance and efficiency, both for individual firms and the sector as a whole.

The key issue is whether the law explicitly provides the instruments that facilitate these activities. Note that each of these nine functions has implications for the prices that will be charged to consumers. In addition, they enable an IRC to meet other regulatory objectives, including the promotion of system expansion and improved service quality. Furthermore, by clearly delineating the responsibilities of the IRC and the government ministry historically responsible for sector oversight, the legal mandate provides for a division of responsibility between the ministry and the agency. If the law provides the tools enabling the agency to gather information and establish incentives for good performance by the regulated firms, then the sector will come closer to meeting the objectives written into the law. Finally, an appeals procedure provides some checks and balances so that activities supporting regulatory decisions are in line with the law.

The Hungarian Communications Authority (HIF) is an example of a regulatory agency without an adequate legal framework. Although created by law, the minister defines HIF's duties. The nine functions noted above are not clearly laid out. In fact, HIF's role can change with every political change. Similarly, in Latin America, presidential decrees have played roles in the creation and operation of "independent" regulatory commissions. For example, an agency scoring high on regulatory scorecards such as OSIPTEL (Peru) has clear laws, but the political system still has the potential to weaken their implementation (Gutierrez, 2001). Presidential decrees can override rulings made by the commission. Only experience will signal to potential investors the actual degree of autonomy for such agencies.

Values: What core principles support ongoing activities of a new government agency? What attitudes must be exhibited by the leaders and professional staff in order to gain the trust of stakeholder groups (customers, investors, and government ministries)? For example, if independence of the IRC is important, how can such independence be best achieved? Similarly, what processes will promote transparency so stakeholders have confidence in the integrity of the system? What types of information are required so that appropriate incentives can be established?

Since values (or operating principles) are often not emphasized when agencies are created, it is helpful to have a definition of the shared values so essential for success. Another term that could be used is the organization's culture. Schein (1992, p. 12) offers the following definition of culture:

Culture is ... a pattern of shared basic assumptions that the group learned as it solved its problems of external adaptation and internal integration, that has worked well enough to be considered valid and, therefore, to be taught to new members as the correct way to perceive, think, and feel in relation to those problems.

Thus, values represent the principles that support the daily activities and vision of the IRC. These must be consistent with meeting the objectives of the agency. A task force for the 
Australian Competition Commission identified nine best practice principles of good regulation:

i. Communication (information to stakeholders on a timely and accessible basis)

ii. Consultation (participation of stakeholders in meetings)

iii. Consistency (across market participants and over time)

iv. Predictability (a reputation that facilitates planning by suppliers and customers)

v. $\quad$ Flexibility (by using appropriate instruments in response to changing conditions)

vi. Independence (autonomy in that decisions are free from undue political influence)

vii. Effectiveness and Efficiency (cost effectiveness is emphasized in data collection and policies)

viii. Accountability (clearly defined processes and rationales for decisions, with appeals)

ix. Transparency (openness of the process)

Based on international experience to date, these principles (or values) need to be present to support the activities or work of IRCs. ${ }^{3}$

We can see how several of these principles are essential for successful regulation.

Participation provides stakeholders with opportunities to provide input into agency deliberations. Without access to the process, external groups will be unable to contribute fresh perspectives on policy alternatives, which leads to insular (and bureaucratic) approaches to solving problems. Since the professional staff of an agency is also a stakeholder, the governance system must ensure their meaningful participation in resolving controversial regulatory problems.

Transparency means that the general public and special interests can see the rationale behind agency decisions. Well-organized communication activities open the process to the light of day, highlight the priorities and analyses underpinning decisions. Again, agency staff determine transparency (through their interactions with stakeholders) and can benefit from the free flow of ideas between groups within the agency. Finally, predictability enables consumers to plan their purchases without undue concern regarding disruptive price changes. In addition, credibility within the international investment community is promoted when investors are able to forecast future trends in regulatory rulings. Internal agency procedures determine the consistency and predictability of decisions to a large extent.

Governance within an agency reflects both legal mandates and agency values. Governance has two components: design (agency structure) and processes (internal and external). The structure of an agency is defined by its relationship to other government entities, while the process determines how the agency relates to other stakeholder groups. Stern and Holder (1999) identify three key elements of agency design: clarity of roles (vis-à-vis the ministry and the operating companies), autonomy (independence from excessive political pressure), and accountability (through appeals procedures and reporting requirements). In addition, they describe three features of the regulatory process that promote the legitimacy and effectiveness of new regulatory agencies: participation, transparency, and predictability. These features of the process relate primarily to external constituencies.

\footnotetext{
${ }^{3}$ Baldwin and Cave (1999, p. 77) have a shorter list for determinants of regulatory legitimacy: (1) Legislative mandate - Is the action or regime supported by legislative authority? (2) Control - Is there an appropriate scheme of accountability? (3) Due Process - Are procedures fair, accessible, and open? (4) Expertise - Is the regulator acting with sufficient expertise? (5) Efficiency - Is the action or regime efficient? Berg (2000) outlines the ACCC principles in greater detail.
} 
Resources: Although budget size is just part of this factor, the level of resources must permit the IRC to complete its assigned functions. Additional considerations are the start-up strategy for the new entity and the kind of leadership required for the IRC. How do funding, the recruitment of professionals, and staff development affect the performance of the IRC and the sector for which it provides oversight?

Resources must be adequate for agency responsibilities. First, the funding mechanism determines both the financial sustainability of the agency as well as its degree of independence. If the political process can be used to punish the IRC for particular regulatory decisions, then the regulatory time horizon will be the same as that of elected officials - the number of months until the next election. In a capital-intensive industry with significant sunk costs, investors will avoid putting their funds into companies subject to the whims of the times. Certainly the IRC remains a creature of the legislature or the executive order that created it. The funding mechanism should promote autonomy and reduce the likelihood of political meddling.

Beyond the level of resources, the mix of resources is relevant to the IRC's ability to engage in activities necessary for its regulatory functions. For example, the selection of commissioners requires that the nomination process recognize that these leaders will determine the effectiveness of the organization. The quality and independence of those appointed to positions of leadership are signals to investors and consumers as to whether the government is truly serious about instituting sector reforms. Finally, experts in finance, engineering, accounting, law, and economics are necessary to analyze policy options. Because these specialists must be recruited and retained, exemption from civil service salary brackets may be necessary to bring salaries up to market. A small staff of qualified professionals is preferable to a huge bureaucracy that lacks expertise and motivation. It should be noted that outside services can be obtained through consulting contracts.

The bottom line is that, without adequate resources, a new IRC will be unable to function effectively. Yet even with resources but without a legal mandate and shared values, an agency is unlikely to engage in activities that support improved sector performance. Figure 1 (described in some detail in Berg, 2000) depicts the many external factors affecting optimal agency design and appropriate regulatory policies. Institutional conditions affect the design and processes of an IRC, which in turn determine the rules and incentives applied to regulated firms and to market participants (Levy and Spiller, 1996). International perceptions, general economic conditions, and the breadth and depth of input markets within the country are factors beyond the IRC's control. Fundamental industry conditions (including technology and demand growth) are also outside the purview of an IRC. However, entry policies and incentives affect industry structure and market behavior (prices, capacity expansion and quality), which, in turn, influence industry performance. Thus, when the legal mandate, agency values, and organizational resources are consistent, performance is more likely to socially acceptable. Thus, after considering a "best case," we will examine situations where one or more of the three factors are inadequate, providing examples of how IRCs have actually addressed lack of congruence among the three factors.

\section{[Insert Figure 1]}




\subsection{Full Congruence}

A well-designed regulatory agency begins with the overlap of three factors. Activities that are mandated by law (or at least not denied the agency), supported by shared values, and covered by the IRC's budget are likely to yield policies that meet the broad policy objectives laid out for the agency. We take this to be the ideal state, recognizing that one or more of these factors is likely to be absent or inadequate for newly created agencies. Furthermore, over the life cycle of government agencies, the factors are likely to change as the law, budgets, or values change. Even if these remain unchanged, the context in which policy decisions are reached can change. These points will be developed in Sections 2 and 3.

Many analysts have characterized the task of regulatory agencies as balancing the interests of three groups: consumers, investors, and government. ${ }^{4}$ Figure 2 makes the system look orderly. However, the task is clearly even more complicated, since the interests of different groups within each constituency can be at odds. In the case of consumers, large industrial consumers have different options than small residential consumers. If today's consumers have a low price that does not permit cost recovery, future consumers will experience deteriorated service quality and potential consumers will be worse off since investments in new connections will not be made. Similarly, investors in incumbent firms will prefer different entry regulations than investors in new suppliers. Finally, government could be viewed broadly as elected officials, bureaucrats, and politicians. The Labor Ministry and the Environmental Protection Agency might not put cost-containment as a priority if it affects their constituencies in a negative way.

\section{[Insert Figure 2]}

The activities of an IRC involve incorporating the concerns and interests of numerous groups into policies that improve sector performance. Thus, the presence of resources, mandate, and values does not make effective regulation easy, but they do make effective regulation possible.

\subsection{Resources and Mandate without Values}

The absence of shared values creates problems for agency decision-making. In particular, new agencies lack a history that can give professional staff insight into how different processes and activities determine the effectiveness of the IRC. Two examples illustrate the problem of having only resources and a legal mandate for performing regulatory functions. One involves the issue of transparency and the other relates to creating shared values.

In the early years of electricity regulation in the United Kingdom, the Director General of the Office of Electricity Regulation (Offer) made regulatory decisions that lacked transparency. This value was balanced against other values and not emphasized. However, later decisions involved a more open communication process, with preliminary findings published by Offer and responded to by stakeholders.

\footnotetext{
${ }^{4}$ For example, see W. Smith (1997) and Berg (2000). In addition, we could add a fourth group: international aid agencies and multilateral funding organizations. These entities play an especially important role in both creating regulatory capacity and facilitating financial transactions, including risk re-allocation. Certainly, they are affected by regulatory actions and put pressure on regulatory commissions.
} 
In the case of the National Electricity Regulator (NER) for South Africa, the entire commission - from cleaning staff to commissioners - went on a Retreat to develop a Mission Statement and identify core values (honesty/integrity, respect, trust, commitment, professionalism, equity, and openness) that could serve as the basis for going forward. Being intentional about creating a new agency's culture is one way to remind all the staff of how important it is to act in ways consistent with shared values.

New agencies that lack the historical experiences to create shared values may turn to incountry staff workshops and to international training courses and conferences to learn what values have been important elsewhere. As commissioners gain experience and professional staff work on issues, they are likely to develop a set of common core attitudes - though the issues are generally so complex that total agreement on every issue is unlikely (and perhaps undesirable).

\subsection{Values and Resources without a Mandate}

The lack of a legal mandate opens up the IRC to challenges if it attempts to take on some function for which it has not been given explicit responsibility. Of course, the agency can argue that the function is implicit in its mandate, but some external determination may be still necessary. Certainly, as part of its regular reporting activities, the IRC should keep the legislative and executive branches informed of how the law affects its ability to achieve regulatory objectives. There is a careful balancing act here, since the IRC is a creature of the executive or legislative branch, it must keep government informed without appearing to overreach its mandate.

For example, if the appeals process is poorly conceived, all the work that goes into preparing sound regulations can go for naught. Similarly, an IRC might lack regulatory authority to request data or even be denied particular instruments when the law precludes some option. For example, it might state that rate of return on rate base regulation must be utilized. Or the agency may have authority but lack power to enforce rules - as when there are no penalties for noncompliance. Furthermore, current industry structure might not yield competitive outcomes in unregulated portions of the sector. Without some role in determining industry structure, the agency is left without an essential regulatory instrument.

Alternatively, since legislative committees write laws that can be hundreds of pages long, ambiguities and inconsistencies can be embodied in the legislation. So the lack of a mandate may be attributable to inconsistencies that ultimately will be determined by the court system or resolved through new legislation. In the meantime, what is a regulator to do?

In Jamaica, under the leadership of Winston Hay, the Office of Utilities Regulation (OUR) has tried to develop a shared vision and promote transparency to make up for unclear laws and contention over modifications of long-term contracts. In particular, did the monopoly contract apply to wireless services or only to wire-line? The contract appeared to deny citizens new services and involved relatively high returns to the incumbent telecommunications firm. Increased public awareness and mutual commitment to "reasonable" modifications in the contract have helped move the system forward - ultimately promoting competition and service 
improvements.

In the case of California, the Public Utility Commission gave a report to the legislature stating what it intended to do regarding deregulation and restructuring of the electricity sector. Given agency values and the priorities for improved sector performance, this policy initiative seemed to offer advantages over the status quo. The agency had the resources necessary to provide supporting studies and to hold town meetings throughout the state during the period leading up to the declaration. It stated that, absent further legislative direction, it intended to move forward in the reform process. The legislature could have acted but did not, so the PUC moved forward. Ultimately the legislature passed a law addressing the issues raised by reform, including treatment of stranded costs. However, the case illustrates how an IRC can be innovative while keeping within the intent of existing legislation. Unfortunately, the California model ended up having some severe problems.

\subsection{Values and a Mandate without Resources}

The complaint of inadequate resources is a universal one. For under-funding to be considered a legitimate problem, the agency should be able to demonstrate that current resources are, indeed, being wisely used to meet the priorities of the organization. That is, the agency is operating on its production possibility frontier and with little or no waste and organizational slack. Tasks and responsibilities are well-defined, links to key activities and outputs are understood, time is not burned in bureaucratic meetings, and staff is working in a cost-effective manner.

In addition, no decision-maker feels that he or she has all the data and analysis necessary for perfect confidence in the regulatory rules ultimately promulgated. ${ }^{5}$ While adequacy of resources is a matter of degree, there certainly can be times when the inability to bring resources to bear on a task results in missed deadlines and/or unexplored (but potentially productive) policy options. An actual instance is described below.

In 1992, the New York Department of Public Service faced some issues in the development of regulatory incentives. Niagara Mohawk had proposed an incentive plan that utilized benchmark comparisons, so that it would be rewarded if its performance exceeded that of predetermined indices. The commission lacked resources to conduct an independent study of the yardstick proposal and wanted to ensure that its professionals fully understood the implications of the program. The company realized that the proposal could not be accepted (or modified) in a timely manner. Thus, it was willing to fund an independent study by a team selected by and reporting to the commission.

The consulting team analyzed the data sources, explored technical features of the proposed cost indices, and described the incentive impacts of the performance-based regulation plan. They also participated in meetings with various stakeholder groups who wanted to ensure that the resulting policy was consistent with their interests. Thus, the sessions facilitated

\footnotetext{
${ }^{5}$ At times, "paralysis by analysis" can result if decision-makers seek perfect knowledge. They must recognize that, when considering the impacts of rule changes, no policy initiative is without risk and that there are no guarantees that all the relevant scenarios have been examined.
} 
communication among the parties and promoted transparency in the development of a proposed incentive plan. The resulting process supported regulatory values and was consistent with the agency’s legal mandate.

The consulting team also examined suggestions by other parties to the discussion. One such proposal for a benchmarking index was found to lack many of the positive features of the company's plan (for an evaluation of the customer bill index, see Berg (1995)). The various stakeholders seemed to feel that the process improved participant understanding of the incentives and the Department of Public Service developed a mutually acceptable plan that made everyone better off. So in this instance, the resources came directly from the company being regulated, yielding an outcome consistent with the values of the regulators (stronger incentives for costcontainment and sharing of savings with consumers).

In Australia, Austel used the same technique for obtaining independent estimates of universal service costs. As telecommunications competition was being introduced, the oversight authority (at that time) wanted to determine the extent of any asymmetric burden on the incumbent - for its investments for universal service. Austel had the industry fund the study, but the consultant reported to Austel.

Remedying the resource problem directly can involve political compromise. If hiring the nephew of the finance minister leads to a sustainable funding, then the option ought not be ruled out. No system is entirely insulated from political pressure. The art of regulation involves knowing when to draw the line, so that principles are not so badly compromised that the credibility and legitimacy of the agency are threatened.

\subsection{Mandate Only}

If the law states that the IRC can do something, presumably there are circumstances when it need not do so. If the activity is perceived as counterproductive (in terms of the impacts on industry performance) or conflicts with agency values (such as transparency or the avoidance of micro-management), then flexibility of response is useful. However, if the law states that the IRC must do something, the situation is more complicated. The long-run solution is to inform policymakers of the implications of following the letter of the law, and then work (behind the scenes) to make the law consistent with best practice regulation.

When an agency emphasizes a particular set of principles and has only minimal funding, a problem arises if the law is inconsistent with those principles. For example, in Argentina's natural gas sector, the law requires the regulatory agency, Enargas, to document the sources of cost savings available to firms. Such information could arise from a detailed management audit, but an agency without the staff and other resources necessary to identify cost-containment opportunities cannot comply with the law. Furthermore, in this case, the purpose of the documentation process was to calculate the dollar savings associated with productivity improvements and to use these to determine the $\mathrm{X}$-factor to be applied to gas distribution companies in a price control review. 
Since this requirement was interpreted as requiring the agency to develop cost-containment programs that companies could adopt to achieve these savings, it placed the IRC in a position of engaging in the micro-management of firms, which ran counter to widely shared agency values. How could these positions be reconciled? To handle the problem in this price review, the agency also decided to examine total factor productivity numbers to gauge the feasibility of plans. Thus, the numbers at least had a reality check while maintaining consistency with legal mandates. Such gyrations may not be desirable over the longer term, since transparency can be threatened if formal and informal processes are not aligned. The key point here is that the formal process (agency identification of firm cost-containment programs as required by law) ended up diverging from the actual process used to estimate the productivity offset (X-factor). ${ }^{6}$

\subsection{Resources Only}

Having excess resources would seem to be the ideal situation. The IRC has an opportunity to invest in complementary resources that "might" be useful in the future. However, there are at least three potential problems with an excessively large budget or staff. First is the temptation to use resources to monitor firms to an excessive degree. For example, the IRC could require monthly reports, instead of quarterly or annual reports, so staff has something to review. More detailed reports could be solicited, reviewed, analyzed, and interpreted. The agency could schedule opportunities for clarification, so professional staff could quiz managers about why certain decisions and financial outlays were made. However, the costs of compliance are nontrivial. In fact, the resulting micro-management not only raises the operating costs of the regulated firm, but it can dampen incentives for cost containment.

There is a case of a Latin American water regulator that obtained much of its staff from the water utility that had been privatized. The “excess” employees from the downsized company were guaranteed employment at the IRC. The result can only be described as a nightmare. Many productive employees were retained by the water utility, which was now in a position to reward managers for high performance. The others were angry and now in a position to regulate the operations of the water utility. Their activities were not consistent with values promulgated within the IRC nor did the law require them. However, the temptation to "get even" was just too great, and the former utility employees negatively affected sector performance.

A second problem is that diseconomies of scale set in with large bureaucracies. Given individual salary caps, funds will likely go to larger numbers of employees rather than to better professionals. Mediocre personnel make mistakes that then have to be remedied by others. The resulting rise in costs is disproportionately large relative to the benefits delivered in terms of meeting mandated sector objectives. Furthermore, "management by meetings" ultimately encourages passivity and discourages initiative within the agency.

The third problem is that fiscal oversight agencies will be monitoring IRC performance. There is benchmarking among regulatory agencies in terms of staffing levels, mix of responsibilities, and sector performance. Excessive resources will ultimately be identified, and

\footnotetext{
${ }^{6}$ An excellent overview of price cap procedures may be found in Green-Pardina (1999)
} 
those responsible for wasting tax money are unlikely to be rewarded. An old proverb states "Beware of making a wish . . . it may come true." This observation is certainly true in the case of wishing for excessive resources.

\subsection{Values Only}

Perhaps the most frustrating situation is to have a clear regulatory vision and supporting set of values, but to be unable to move forward because of lack of legal mandate and severe resource constraints. However, one needs to assess whether values unsupported by law or funding are really appropriate (or essential). When values, such as transparency or consistency, are deemed worthy of being defended, there still are regulatory strategies that can move the agency in the right direction.

As was noted earlier, in the case of the OUR in Jamaica, the agreement inherited by regulators provided a fixed return (16\%) and limited entry. The agency challenged the entry provisions, arguing that the government had not intended to give control over the spectrum to the incumbent telecommunications supplier. Ultimately, the process yielded a compromise, but the absence of legal precedents did not make the process easy.

The Peruvian water regulator (Sunass) faced a different type of problem (Corton, 2000). The agency oversees 45 municipal water authorities, 44 of them owned by municipalities and one SEDAPAL, Lima's supplier - owned by the central government. It lacked instruments for rewarding good performance or penalizing poor performance. So leaders in the agency decided that data collection and benchmarking would at least start the process of identifying poor performers and good performers. The process has not been easy, since uniform systems of accounts require careful development. The initial data submissions were subject to "revision" by the water utilities, partly because the rankings proved embarrassing to some managers, but also because the local authorities filled out forms incorrectly. Now other government agencies see how some public funding was wasted: many municipalities focused on political patronage rather than economic efficiency and system expansion. There is likely to be more pressure for reform, and perhaps Sunass will be given more instruments to promote cost containment and service improvements in the water sector.

The Norwegian electricity regulator took basically the same approach for the more than 200 municipal distribution utilities. In this case, the regulator had legal authority over distribution pricing, so besides having "League Tables" that exposed poor performance to the general citizenry, the regulator based the $\mathrm{X}$ factor (for price reviews for each utility) on the firm's distance from the efficiency frontier. Poorly performing firms with more room for improvement in operations had their prices set to fall more rapidly than those of well-performing distribution systems. An implicit message from the regulator was that some mergers might be called for to achieve scale economies. Such benchmarking characterizes many regulatory regimes.

Other factors reinforced the benchmarking initiative in Norway. However, for many developing countries, the law is ambiguous regarding an IRC's access to certain types of information. In such cases, the regulated utility might decline to submit the report or just provide poorly documented data. If there are no resources to press the case further or to estimate the data 
from firm-specific models, then the IRC is left with a dilemma. In one instance, a new IRC was unable to obtain information that it viewed essential for determining whether current prices were allowing "excessive" returns. When non-cooperation was the response from the firm, the agency adopted a relatively simple approach in establishing rates based on "comparable" firms in another country. This strategy was not in violation of the law, and ultimately led the firm to be more forthcoming, since the alternative was so unpleasant.

In these situations, one long-term strategy is to communicate with those responsible for the law and for funding. If the agency has credibility with the government, investors, and consumers, the various stakeholders are more likely to accept the arguments of the IRC and provide support for factors that reinforce IRC principles. Another strategy is to interpret the mandate broadly and give others opportunities to intervene as appropriate. The case of deregulation in California really could fit into this situation as well. To reach its policy conclusion, the Public Utilities Commission held an extensive series of workshops, ultimately relying heavily on consensus building among stakeholders. The process was not inexpensive, but participants were the ones making investments in studies and extensive discussions. The vision of the regulators triggered a new initiative, even though resources for studies were limited and the legal mandate was somewhat in question.

Let us now take another cut through these issues and consider which factors are likely to be binding constraints over the life cycle of an IRC.

\section{Lessons from the Regulatory Life Cycle}

Some observers of the regulatory process have described agencies as having a regulatory life cycle. Beginning its existence with public perceptions that a "problem" exists and that a new agency can resolve the problems facing the sector, the commission starts with youthful energy, protecting consumers and promoting objectives laid out in the legislation, but ends up as a calcified agency that protects producers (Bernstein, 1955). Thus, regulators eventually succumb to the interests of the firms they regulate or to politically powerful consumer groups. It is useful to consider how the three factors (legal mandate, resources and values) come into play in this story of "regulatory capture and atrophy".

\subsection{Process Leading to Birth}

Many regulatory agencies are established in crisis situations. When existing arrangements do not lead to strong sector performance, initiatives to achieve reform objectives are responses to a litany of complaints about public sector firms behaving as monopolies, requiring public subsidies, operating inefficiently, squelching potential competitors, providing poor service, and not innovating. It would be naive to think that privatization and/or an IRC could remedy these problems easily. Institutions develop over a period of decades, and no institutional innovation or policy change is likely to improve performance painlessly.

Thus, broad public concerns or an actual crisis generally provide the stimulus for reform. If expectations are too high, the IRC is doomed to failure, especially when those currently receiving utility service are paying low (below-cost) prices. Those without service will not immediately benefit from rate re-balancing, but those individuals whose prices rise will certainly 
have much to say. The lack of targeted subsidies and non-transparency of past policies means that there is much work for a new IRC.

\subsection{Infancy: Learning the Ropes}

A newly born institution is somewhat fragile. Those who lost power when the IRC was established are now in a position to cause trouble. Managers placed under new pressures for cost containment may not appreciate being held accountable for improved performance. "What have you done for me lately?” is heard from various consumer groups. The press can become the mouthpiece for special interests that did not like the consequences of sector reform. Finally, the general citizenry is likely to be unaware of the new tasks that have been assigned the new agency.

During this early period, the commissioners and professional staff are learning the ropes as well. The agency has to develop procedures consistent with its values and with its legal mandate. These procedures are then tested in the interactions with various stakeholder groups. Often the data are quite inadequate, but establishing a uniform system of accounts and starting data collection are two urgent tasks that will bear fruit only later. Internal task forces at the IRC might be utilized to address particular issues to get groups thinking “out of the box". In the process, relationships within the IRC will not necessarily match the published organizational chart. For example, the Mexican IRC (Comision Reguladora de Energia-CRE) has turned to interdisciplinary teams as a vehicle for developing policies to improve sector performance. ${ }^{7}$ The individual commissioners participate in task forces, thus involving the leadership of the IRC in the technical discussions that lead to recommendations on regulatory rules.

In other countries, IRC commissioners maintain some distance from the staff, operating more like judges than "team leaders." Professional staff present cases, and commissioners exercise judgment regarding the impact of alternative rulings on allowed rates of return and/or on price levels and structures.

Another example of operations in newly created IRCs is Pakistan's National Electric Power Regulatory Authority (NEPRA). In 1999, Pakistan's electricity regulatory agency faced a unique situation when it held its first public hearing on prices charged by the national utility. ${ }^{8}$ The new agency was determining whether prices were remunerative. This situation could be interpreted as a test for the regulators. Did they really have authority over the utility? Was it necessary for the utility to participate in public meetings held to obtain citizen input? In any event, no representatives of the utility were present at the start of the hearing.

The commission chairman responded forcefully, stating that without representatives to answer clarifying questions, the utility's prices would remain the same as in the past. The commission gave the utility two hours to make an appearance. Within an hour, a team of junior executives walked into the hearing room. The utility appeared to conclude that the IRC had

\footnotetext{
${ }^{7}$ Hector Olea, presentation at the PURC/World Bank International Training Program on Utility Regulation and Strategy, June 1997. Under Olea's leadership the CRE illustrates how an agency can be transformed into an active sector regulator. He introduced stakeholder input, opening the process through improved information, publicly announced meetings, and more thorough analysis of proposals.

8 This description is based on conversations with Ali Nawaz Memon, the first chairman of NEPRA.
} 
authority and the meeting was a legitimate way to communicate to the IRC and the general public. The values of the new IRC - to promote transparency and facilitate communicationwere sustained.

\subsection{Youth: Expertise and Initiative}

One could argue that the most exciting phase occurs after the first few years. A vision has been articulated and procedures established. The activities are consistent with the legal mandate and the resource base of the organization. The firms subject to regulation have accepted the new system, and enough time has passed by to demonstrate some success and to identify areas for change. This phase of the regulatory life cycle has the potential to have significant impact on industry performance as market participants develop their own strategies within the rules of the game promulgated by the agency.

Samarajiva, former Director General of Telecommunications of Sri Lanka (1998-99), describes the first decade of the regulatory authority, shedding light on the evolution of a young IRC. Although established as an "under-funded" governmental department in 1991, greater independence was achieved in 1997. So, in a sense, the infant agency had been starved of resources and its legal mandate was not exploited. According to Samarajiva, the IRC began to take new initiatives involving public hearings on billing and tariff determination. Public input led to the incumbent's withdrawing its opposition to itemization on bills. At the same time, interconnection proceedings were instituted. Transparency and participation were two values given significant attention by the Telecommunications Regulatory Commission (Gunawardene, 2000).

Samarajiva argues that public notice and public hearings on issues of popular concern were important during this phase of the agency's development. He contrasts the strategic emphasis of his agency with that of India:

Irrespective of the legislative mandate, fledgling regulatory agencies must proactively take on high-profile public-interest tasks such as improving connectivity in rural areas and protecting consumers from operator abuse. If not, they will lack the legitimacy to perform any of their functions, including those of ensuring the continued inflow of investment and the prevention of disinvestment. The perception of an emphasis on pure competition-enhancing measures by the Telecommunications Regulatory Authority of India (TRAI), as against those with more popular appeal such as universal access and consumer protection, may have contributed to its loss of legitimacy, first in the eyes of the media, and then in the eyes of the government. The TRAI also suffered from the unfortunate integration of operational and policy functions in the incumbent Department of Telecommunications and the undeveloped state of competition in India at that point. The alignment of the policy and operational agencies created a powerful force that overwhelmed a regulatory agency that was buttressed solely by expertise and statute, and lacked broad legitimacy and the strategic support of competitive entrants. (Samarajiva 2000b)

A danger of the Youth Stage is that a sense of populist urgency overwhelms the shared desire for continuity. If agency values change, then stakeholders need to be made aware of the new 
priorities. If stakeholders find out indirectly, the investors and consumers may not find the resulting surprise acceptable. Characterizing this phase in terms of the three factors is not simple. At least shared experiences ought to have led to a regulatory culture that is being transmitted to new staff. Regulatory decisions represent precedents that anchor change and thus make the outcomes of price reviews more predictable. The problem with such anchoring is that it can prove dysfunctional in the next phase if the agency does not adapt to the technological tides and/or other winds of change.

\subsection{Maturity: A “Steady-State”}

When has maturity been achieved? For a government agency, the answer might be when processes are handled in a perfunctory manner. This state of deliberative decision-making can be a welcome respite from the uncertainties associated with the early years of the IRC. Some of the excitement is gone, but stakeholders can review the agency's record and the sector's performance with some sense of perspective.

For nations with low service penetration, one could argue that maturity is not achieved until the universal service objective appears within reach. Furthermore, service quality needs to be brought into the set of objectives as well. Both penetration mandates and quality standards are often specified in a franchise contract or via regulatory decisions. Clearly, customers need some way to provide input into the process so that the multiple objectives can be balanced in socially acceptable ways. Facilitating stakeholder participation and involving consumer associations in the process can take time. ${ }^{9}$

This stage of the regulatory life cycle can be characterized by a number of features. Regulatory processes are well established. Priorities are widely accepted. The activities of the IRC have evolved to suit the values of the organization. Furthermore, there is greater likelihood of congruence in terms of resource availability, the legal mandate, and values. The law may, in fact, still be the same one that created the agency (as with the U.S. Federal Communications Act of 1934, which was operative until 1996). Market participants are comfortable with the regulatory regime, perhaps too comfortable. Nevertheless, this phase might be viewed as a longterm goal for many: no crises, no major policy shifts.

Of course, technological change or demand growth can transform an industry from a natural monopoly to a potentially competitive industry. When regulatory agencies attempt to apply old rules to new situations, there is danger that they are falling into the final stage of the cycle of regulation: senility.

\subsection{Potential Senility: Maintaining the Status Quo}

A dysfunctional stage arises if the government agency does not have mechanisms for renewal and reorientation. Let us use the United States to illustrate how regulatory agencies can harm economic efficiency. Many commentators have viewed the regulation of surface transportation as long outliving its usefulness. In the 1950s and 1960s, the Interstate Commerce Commission

\footnotetext{
${ }^{9}$ Note that service reliability is costly. Some customer groups might prefer a low quality of service (low continuity, for example) in exchange for a lower tariff or for more rapid penetration.
} 
presided over the decline of railroads as it limited competition with the trucking industry. Railroads were actually prevented from responding to their loss of market share-all in the name of "balanced" transportation. Policies seemed to be based on inappropriate shared values; these were views of the transportation sector that might have been true in the Great Depression of the1930s, but were no longer relevant. Similarly, the Federal Communication Commission protected broadcasters from the emerging cable industry in the 1960s.

Protectionism seems to characterize this phase of regulation, as agencies identify with incumbent suppliers and existing technologies. However, firms cannot be completely shielded from technological innovations and changes in consumer preferences. If an IRC finds itself stagnating, then the call for reformation or dissolution is around the corner. The deregulation of the airlines industry and dissolution of the Civil Aeronautics Board (CAB) in the United States in 1975 is an example. It illustrates how political systems can reform regulation when there are convincing case studies of the efficacy of competition and empirical evidence of the positive impacts of contestability in industry performance. However, network industries such as airline transport can still be plagued by problems when hub airport capacity is not expanded and entry barriers are high (access to gates, landing rights, and reservation systems). Nevertheless, A. E. Kahn demonstrated regulatory leadership in changing the direction of the agency and promoting entry - even without a change in legislation. The law set a standard that the CAB should promote the "public interest": Kahn and his fellow regulators concluded that performance under protectionist policies was dismal (McCraw, 1984). Consumers were not protected from high prices when firms were protected from competition.

\section{Concluding Observation}

This paper describes how the creators of new institutions face numerous challenges. Experience in developed and developing nations demonstrates that many problems have been successfully met, but some problems really have no unique solutions. Words written in another context remain relevant when thinking about how IRCs develop. These new agencies

“. . . had to be built up from the ground in accord with desirable goals, and the goals were modified by the objective conditions which confronted the builders. This is the nature of an experiment, where ideas guide activity to test certain conclusions and reach intended outcomes” (Koch, 1961, p. 125).

In the context of government, Koch argues that trial and error represents the typical learning style for leaders in new settings. In the case of regulatory agencies, the main corrective mechanisms are feedback from various stakeholder groups and performance in other countries. When the outcome or performance falls short of reasonable expectations, it is time for systematic study and new hypotheses regarding what will work in the institutional setting in which the agency finds itself. The three binding constraints represent a starting point for that analysis. However, changing market and institutional conditions also determine how broad regulatory policies and specific case decisions affect sector performance. 


\section{Bibliography}

Baldwin, Robert, and Martin Cave. 1999. Understanding Regulation: Theory, Strategy, and Practice. Oxford University Press.

Berg, Sanford V., Ali Nawaz Memon and Rama Skelton. 2000. "Designing an Independent Regulatory Commission”. Public Utility Research Center Working Paper.

. 2000. "Developments in Best-Practice Regulation: Principles, Processes, and

Performance”. Electricity Journal, July, 11-18.

. 1995. "The Customer Bill as an Index of Performance". Electricity Journal, January/February, 54-59.

Bernstein, Marver H. 1955. Regulating Business by Independent Commission. Princeton, NJ: Princeton University Press.

Corton, Maria Luisa. 2000. "Performance Efficiency in Infrastructure: The Water Sector in Peru." Master's thesis, University of Florida Department of Economics, Gainesville.

Green, Richard and Martin Rodriguez Pardina, Resetting Price Controls for Privatized Utilities: a Manual for Regulators, Economic Development Institute of the World Bank, 1999, iv-109.

Gunawardene, Palitha Silva. 2000. “Consumers” Role in Telecom Regulation: A Sri Lankan Perspective,” NRRI Quarterly Bulletin 20(4): 311-18.

Gutierrez, Luis, “An Index of Telecommunications Regulatory Frameworks in the Context of Privatization and Competition Reform,” PURC Working Paper, 2001.

Koch, Adrienne. 1961. Power, Morals and the Founding Fathers. Ithaca, NY: Cornell University Press.

Levy, B. and Pablo T. Spiller (eds.). 1996. Regulations, Institutions, and Commitment, Cambridge University Press.

McCraw, T. K. 1984. Prophets of Regulation: Charles Francis Adams, Louis D. Brandeis, James M. Landis, and Alfred E. Kahn. Cambridge, MA: Harvard University Press.

Samarajiva, Rohan. 2000(a). "Establishing the Legitimacy of New Regulatory Agencies.” Telecommunications Policy 24 (3) 183-187.

. 2000(b). "The Role of Competition in Institutional Reform of Telecommunications: Lessons from Sri Lanka”. Telecommunications Policy 24 (8/9) 699-717.

Schein, Edgar H. 1992. Organizational Culture and Leadership, $2^{\text {nd }}$ ed. San Francisco: JosseyBass Publishers. 
Smith, Warrick. 1997. "Utility Regulators—Roles and Responsibilities,” In Public Policy for the Private Sector, The World Bank Group.

Stern, Jon, and Stuart Holder. 1999. "Regulatory Governance: Criteria for Assessing the Performance of Regulatory Systems-An Application to Infrastructure Industries in the Developing Countries of Asia”. Utilities Policy 8, 33-50. 
